\title{
PERFIL SENSORIAL E ACEITABILIDADE DE AMOSTRAS DE ÁGUA- DE-COCO OBTIDAS POR DIFERENTES PROCESSOS DE FABRICAÇÃO
}

\author{
LAURA FIGUEIREDO ABREU * \\ ANDREIA VALENÇA ARAÚJO * \\ EDER AUGUSTO FURTADO ARAÚJO * \\ ÂNOAR ABBAS EL-AOUAR * \\ DORA NEUMANN * \\ MARCÍLIO MACHADO MORAIS ** \\ MARIA APARECIDA AZEVEDO PEREIRA DA SILVA ***
}

\begin{abstract}
O presente estudo teve como objetivo caracterizar amostras de água-de-coco, comercializadas em grandes supermercados e hipermercados da região sudeste e correlacionar tais características com os diferentes tipos de tecnologia de fabricação empregados. Utilizou-se a análise descritiva quantitativa para levantar o perfil sensorial de três marcas comerciais de água-de-coco (resfriada, congelada e esterilizada), disponíveis no mercado de Campinas, SP (BRASIL), e avaliou-se a aceitação das amostras pelos consumidores mediante teste afetivo. Observou-se que as águas-de-coco estavam sensorialmente descaracterizadas, apresentando sabores e aromas estranhos descritos como água tônica, ferrugem e pútrido, além de baixa aceitação. Tal resultado pode estar diretamente relacionado ao tipo de processamento aplicado ao produto, evidenciando a necessidade de rápida melhoria das linhas de processamento de água-de-coco.
\end{abstract}

PALAVRAS-CHAVE: ÁGUA-DE-COCO; ANÁLISE SENSORIAL.

\section{INTRODUÇÃO}

A água-de-coco ou endosperma líquido do Cocos nucífera (MEDINA et al., 1980), bebida natural e pouco ácida ( $\mathrm{pH}=5,0)$, é constituída de água (93\%), sais minerais, açúcares, substâncias nitrogenadas e gorduras (CAMPOS et al., 1996). Sua composição sofre influência da variedade

* Pós-graduandos da Faculdade de Engenharia de Alimentos (FEA), Universidade Estadual de Campinas (UNICAMP) (e-mail: laura_fabreu@yahoo.com.br).

** Pós-graduando da Faculdade de Engenharia Química (FEQ), UNICAMP.

*** Professora, Doutora em Ciência e Tecnologia de Alimentos, Departamento de Planejamento Alimentar e Nutrição (DEPAN)/ FEA/UNICAMP. 
do coco (anão, gigante e híbrido) e do tempo de maturação da fruta, entre outros fatores (SREBERNISH, 1998; ARAGÃO, 2002). A água-decoco combina sais e açúcares que a tornaram conhecida como ótimo repositor hidroeletrolítico, similar às bebidas isotônicas de alto consumo entre desportistas. Entre 1995 e 2000, a área de plantações de coqueiros tipo anão aumentou de 25 para 50 mil ha, devido principalmente aos investimentos das indústrias de água-de-coco (RANIERI, 2000).

No interior do fruto, a água-de-coco conserva-se por longo período em temperatura ambiente. Entretanto, após sua extração torna-se perecível devido à sua composição propícia ao crescimento microbiano (MEDINA et al., 1980; CAMPOS et al., 1996).

O desenvolvimento de novas tecnologias permitiu aumentar consideravelmente a vida-útil da água-de-coco após a extração, a qual pode ser encontrada no mercado nas formas congelada, resfriada e esterilizada.

A água-de-coco congelada, em algumas situações, não sofre nenhum tipo de tratamento ou adição de conservantes, sendo preservada apenas pelo congelamento $\left(-18^{\circ} \mathrm{C}\right)$. Entretanto, tem sido recomendada a pasteurização antes do congelamento como prevenção às falhas que podem ocorrer na cadeia de frio durante a comercialização. Na forma resfriada pode ser pasteurizada ou não, adicionada de conservantes e mantida sob condições de refrigeração $\left(1-10^{\circ} \mathrm{C}\right)$. O produto nãopasteurizado apresenta vida-útil geralmente de 3 dias, sob refrigeração. Já a água-de-coco pasteurizada pode atingir 6 meses de vida-útil, quando acidificada $(\mathrm{pH}<4,5)$ e adicionada de conservantes (ARAGÃO, 2002).

A água-de-coco esterilizada sofre tratamento térmico por ultra-alta temperatura (UHT em inglês), adição do conservador metabissulfito de sódio e envase asséptico em embalagens cartonadas. Difere das demais por ser proveniente de coco maduro, constituindo subproduto das indústrias de processamento de copra (coco ralado, leite de coco e outros) (RANIERI, 2000; ARAGÃO, 2002). Como conseqüência, apresenta maior teor de gorduras e proteínas (SREBERNISH, 1998), além de ser obtida de cocos da variedade híbrida ou gigante e não da variedade anão como a água-de-coco verde (SOCÔCO, 2001).

As etapas de extração, formulação e tratamento térmico podem alterar completamente as características sensoriais da água-de-coco durante a sua industrialização (LEBER, 2001). 
Este trabalho teve como objetivo determinar o perfil sensorial de três diferentes amostras comerciais de água-de-coco (resfriada, congelada e esterilizada), mediante análise descritiva quantitativa e avaliar a aceitabilidade das mesmas.

\section{MATERIAL E MÉTODOS}

\subsection{AMOSTRAS}

Foram avaliadas amostras comerciais de água-de-coco congelada, resfriada e esterilizada, adquiridas em grandes supermercados e hipermercados da região de Campinas (SP). A amostra congelada foi previamente descongelada sob refrigeração por 24 horas e as demais mantidas sob refrigeração até o momento da realização dos testes. Foram servidos $30 \mathrm{~mL}$ de cada amostra em béqueres de $50 \mathrm{~mL}$ em bandejas térmicas a fim de que fosse mantida temperatura aproximada de $10^{\circ} \mathrm{C}$. Os testes foram realizados em cabines individuais, sob luz branca, com controle da iluminação e da temperatura, no Laboratório de Análise Sensorial, Departamento de Planejamento Alimentar e Nutrição (DEPAN), Faculdade de Engenharia de Alimentos (FEA), Universidade Estadual de Campinas (UNICAMP).

\subsection{ANÁLISE SENSORIAL}

O perfil sensorial de cada amostra foi determinado por julgadores selecionados e treinados, segundo a metodologia de análise descritiva quantitativa (STONE e SIDEL, 1985; SILVA, 2002). Avaliou-se a aceitabilidade das amostras mediante testes afetivos com a participação de consumidores do produto.

\subsubsection{Análise Descritiva Quantitativa (ADQ)}

\subsubsection{Desenvolvimento da Terminologia Descritiva}

Desenvolveu-se a terminologia descritiva das amostras de água-de-coco pelo Método de Rede (MOSKOWITTZ, 1983; SILVA, 2002). Todas as amostras foram apresentadas ao mesmo tempo aos julgadores em cabines individuais de avaliação sensorial. Foi solicitado que os julgadores descrevessem similaridades e diferenças entre as amostras com relação à aparência, ao aroma e sabor, conforme a ficha mostrada na Figura 1. 


\section{FIGURA 1 - FICHA UTILIZADA PARA APLICAÇÃO DO MÉTODO DE REDE}

Nome: Data:

Por favor, avalie inicialmente, a APARÊNCIA das três amostras. Agrupe as duas amostras mais similares quanto a APARÊNCIA e descreva abaixo, em que elas são similares e em que elas diferem da terceira amostra. A seguir, repita o mesmo procedimento com relação ao AROMA E SABOR das amostras.

ATRIBUTOS Similaridades Diferenças

Aparência:

Aroma:

Sabor:

Em cada sessão, os julgadores geravam seus próprios termos para descrever as similaridades e diferenças entre as amostras agrupadas em pares. Em seguida discutiam em grupo sob a supervisão de um líder, com o intuito de agrupar termos descritivos semelhantes e gerar amostras de referência para cada atributo. Sessões suplementares foram realizadas para o treinamento dos julgadores com as amostras e as referências sugeridas. Mediante discussão em grupo, a equipe elaborou de forma consensual a lista de definição dos termos descritivos e a ficha de avaliação das amostras. Nessa última, a intensidade de cada atributo foi ancorada nos extremos das escalas utilizadas.

\subsubsection{Treinamento e Seleção Final da Equipe de Análise Descritiva}

Durante as sessões de treinamento, os julgadores foram solicitados a avaliar a intensidade de cada atributo para as três diferentes amostras de água-de-coco utilizando a Ficha de Avaliação. Materiais de referência e a definição de cada descritor foram colocados à disposição dos julgadores em cada sessão. Encerrou-se a fase de treinamento quando os julgadores não demonstraram dificuldades em avaliar as amostras utilizando a ficha consensualmente desenvolvida.

A etapa de seleção final dos julgadores treinados para a análise descritiva foi conduzida pela avaliação das amostras de água-de-coco em três repetições (sessões). As amostras foram servidas de forma monádica, sendo solicitado aos julgadores que enxaguassem a boca com água em 
temperatura ambiente entre uma amostra e outra. Efetuou-se a análise de variância dos resultados individuais para cada atributo, tendo como fontes de variação as amostras e as repetições. Os julgadores que apresentaram bom poder discriminativo $\left(\mathrm{pF}_{\text {amostra }}<0,30\right)$, boa reprodutibilidade nos julgamentos $\left(\mathrm{pF}_{\text {repetição }}>0,05\right)$ e consenso com os demais membros da equipe foram selecionados para compor a equipe (DAMÁSIO e COSTELL, 1991).

\subsubsection{Perfil Sensorial das Amostras de Água-de-coco}

O perfil sensorial das três amostras de água-de-coco foi determinado por cinco julgadores treinados e provenientes da seleção final da equipe sensorial descritiva. Utilizando a Ficha de Avaliação apresentada na Figura 2, os julgadores avaliaram as amostras em três repetições (sessões), utilizando delineamento experimental de blocos completos casualizados. Os resultados foram analisados pelo programa estatístico SAS (1996) e submetidos à análise de variância (fontes de variação: amostras e julgadores), teste de Tukey $(\alpha=0,05)$ e análise de componentes principais (ACP).

\section{FIGURA 2 - FICHA UTILIZADA NO TREINAMENTO E AVALIAÇÃO DAS AMOSTRAS}

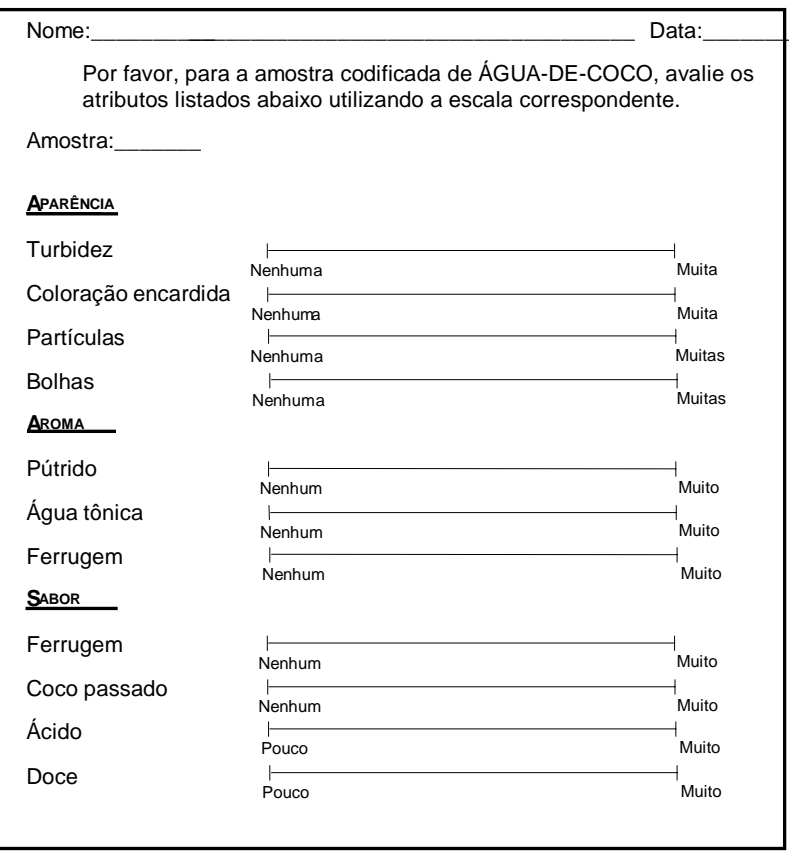




\subsubsection{Teste de Aceitação das Amostras de Água-de-coco}

A aceitabilidade das três amostras foi avaliada com a participação de 30 consumidores de água-de-coco. Os julgadores avaliaram as amostras utilizando escala hedônica estruturada mista de nove pontos, conforme apresentado na Figura 3. Os dados sensoriais foram submetidos à análise de variância, teste de Tukey $(\alpha=0,05)$ e histograma de freqüência (nível de aceitação do produto versus \% de julgadores).

\section{FIGURA 3 - FICHA UTILIZADA PARA O TESTE DE ACEITAÇÃO}

Nome:
Por favor, prove as amostras codificadas de água-de-coco da esquerda para direita e, utilizando a
escala abaixo, descreva o quanto você gostou ou desgostou de cada amostra.
9 Gostei muitíssimo
8 Gostei muito
7 Gostei moderadamente
6 Gostei ligeiramente
5 Nem gostei / nem desgostei
4 Desgostei ligeiramente
3 Desgostei moderadamente
2Desgostei muito
Aesgostei muitíssimo
Amostra:

\section{RESULTADOS E DISCUSSÃO}

\subsection{TERMINOLOGIA DESCRITIVA}

A equipe de julgadores gerou 11 termos para descrever as similaridades e diferenças entre as amostras de água-de-coco. Na Figura 4 estão detalhadas as definições de cada descritor com as respectivas referências, utilizadas para o treinamento dos julgadores.

A intensidade dos atributos sensoriais foi avaliada em escalas nãoestruturadas de nove centímetros, ancoradas em seus extremos com os termos nenhum/muito (Figura 2). 


\section{FIGURA 4 - DEFINIÇÕES E REFERÊNCIAS DOS DESCRITORES*}

- AparÊncia

Turbidez. característica referente ao grau de opacidade das amostras.

Nenhuma: água filtrada.

Muita: $40 \mathrm{~mL}$ de água filtrada +2 gotas de leite integral marca PARMALAT.

Coloração encardida: água tendendo para coloração castanho-clara (água barrenta).

Nenhuma: água filtrada.

Muita: $30 \mathrm{~mL}$ de água filtrada $+2,5 \mathrm{~mL}$ de guaraná sem gás marca ANTARCTICA.

Partículas: água com presença de pequenas partículas brancas em suspensão.

Nenhuma: água filtrada.

Muitas: $40 \mathrm{~mL}$ de água filtrada + papel higiênico branco lixado $(0,0020-0,0030 \mathrm{~g})$ sobre peneira Tyler $20-24(0,84-0,71 \mathrm{~mm})$.

Bolhas: água com presença de pequenas bolhas distribuídas nas paredes do recipiente.

Nenhuma: água filtrada.

Muitas: $25 \mathrm{~mL}$ de água filtrada $+1,5 \mathrm{~g}$ de sal de frutas marca ENO, imediatamente após efervescência.

- Aroma

Pútrido: aroma característico de água de esgoto.

Nenhum. água filtrada.

Muito: água-de-coco verde (variedade Anão, com sete meses de maturação e cinco dias de colheita, adquirido na CEASA de Campinas - SP) com duas semanas de extração mantida em geladeira a $7^{\circ} \mathrm{C}\left(5,5^{\circ}\right.$ Brix e $\left.\mathrm{pH}=5,0\right)$.

Água tônica: odor característico de água tônica.

Nenhum. água filtrada.

Muito: amostra de água tônica Quinino marca SCHWEPPES diluída na proporção 1:1.

Ferrugem. odor característico de metal enferrujado.

Nenhum. água filtrada.

Muito: metal enferrujado mantido em tulipa de vidro coberta com vidro de relógio.

- SABOR

Ferrugem: sabor característico de água ferruginosa.

Nenhum. água-de-coco verde (variedade Anão, com sete meses de maturação e cinco dias de colheita, adquirido na CEASA de Campinas - SP).

Muito: solução de $0,15 \mathrm{~mL}$ de sulfato ferroso heptahidratado (16,6\% p/p) em $200 \mathrm{~mL}$ de água-decoco verde (variedade Anão, com sete meses de maturação e cinco dias de colheita, adquirido na CEASA de Campinas - SP).

Ácido: gosto ácido característico.

Pouco: solução $0,02 \% \mathrm{p} / \mathrm{v}$ de ácido cítrico monohidratado em água-de-coco verde (variedade Anão, com sete meses de maturação e cinco dias de colheita, adquirido na CEASA de Campinas $\mathrm{SP})$.

Muito: solução 0,08\% p/v de ácido cítrico monohidratado em água-de-coco verde (variedade Anão, com sete meses de maturação e cinco dias de colheita, adquirido na CEASA de Campinas - SP).

Doce: gosto característico de solução de soro caseiro (sacarose + cloreto de sódio em água).

Pouco: água-de-coco verde (variedade Anão, com sete meses de maturação e cinco dias de colheita, adquirido na CEASA de Campinas - SP).

Muito: solução $5 \%$ p/v de sacarose em água-de-coco verde (variedade Anão, com sete meses de maturação e cinco dias de colheita, adquirido na CEASA de Campinas - SP).

Coco passado: sabor de água-de-coco velho (excessivamente maduro).

Nenhum. água-de-coco verde (variedade Anão, com sete meses de maturação e cinco dias de colheita, adquirido na CEASA de Campinas - SP).

Muito: água-de-coco verde (variedade Anão, com sete meses de maturação e cinco dias de colheita, adquirido na CEASA de Campinas - SP) com 24 horas de extração armazenada a temperatura ambiente.

*Características avaliadas com amostras em recipiente de vidro transparente, sob luz branca artificial. 


\subsection{PERFIL SENSORIAL}

Os perfis sensoriais de cada uma das três amostras de água-de-coco processadas, obtidos pela análise descritiva quantitativa dos produtos estão expressos em gráfico aranha (Figura 5). O centro da figura representa o ponto zero da escala de atributos, enquanto a intensidade aumenta do centro para a periferia.

\section{FIGURA 5 - CONFIGURAÇÃO DA ANÁLISE DESCRITIVA QUANTITATIVA (ADQ) DAS AMOSTRAS AVALIADAS}
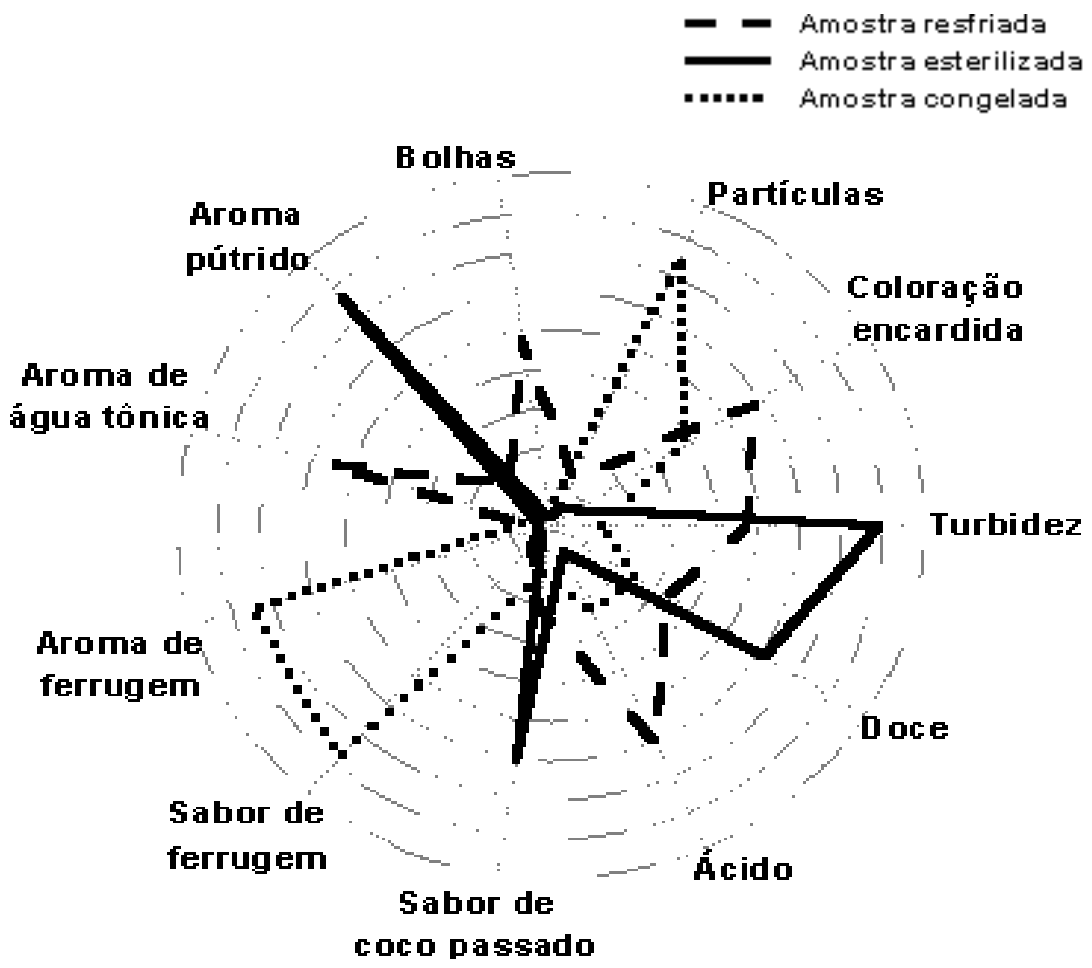

Os resultados mostrados na Figura 6 são complementados pela Tabela 1, que apresenta as médias obtidas pelas amostras em cada atributo e os resultados do teste de Tukey.

A água-de-coco resfriada (Figura 5 e Tabela 1) distinguiu-se das demais por apresentar gosto ácido, aparência de encardida e aroma de água tônica de forma acentuada e maior presença de bolhas $(p<0,05)$. A água- 
de-coco esterilizada caracterizou-se pela maior turbidez e pela intensidade de aroma pútrido, gosto doce e sabor de coco passado $(p<0,05)$. A águade-coco congelada caracterizou-se por apresentar acentuado sabor $\mathrm{e}$ aroma de ferrugem e maior presença de partículas $(p<0,05)$.

\section{TABELA 1 - MÉDIA DAS NOTAS ATRIBUÍDAS PELOS JULGADORES POR ATRIBUTO PARA AS AMOSTRAS}

\begin{tabular}{|c|c|c|c|c|c|c|}
\hline \multicolumn{2}{|c|}{ Atributos } & Amostra 1 & Amostra 2 & Amostra 3 & $\begin{array}{c}{ }^{*} \mathrm{~F} \\
\text { (amostras) }\end{array}$ & DMS \\
\hline \multirow{4}{*}{ Aparência } & Turbidez & $4,7^{b}$ & $7,9^{a}$ & $1,2^{c}$ & $147,8^{*}$ & 0,96 \\
\hline & Encardida & $5,8^{a}$ & $0,8^{c}$ & $3,8^{b}$ & $41,1^{*}$ & 1,38 \\
\hline & Partículas & $1,3^{b}$ & $0,6^{\mathrm{b}}$ & $7,5^{a}$ & $253,4^{*}$ & 0,83 \\
\hline & Bolhas & $4,8^{a}$ & $0,2^{b}$ & $0,4^{\mathrm{b}}$ & $45,1^{*}$ & 1,35 \\
\hline \multirow{3}{*}{ Aroma } & Pútrido & $1,5^{b}$ & $7,7^{\mathrm{a}}$ & $0,2^{c}$ & $152,9^{*}$ & 1,12 \\
\hline & Água tônica & $5,6^{a}$ & $0,3^{b}$ & $0,5^{b}$ & $68,7^{*}$ & 1,27 \\
\hline & Ferrugem & $0,3^{b}$ & $0,4^{\mathrm{b}}$ & $7,5^{a}$ & $1355,4^{*}$ & 0,39 \\
\hline \multirow{4}{*}{ Sabor } & Ferrugem & $0,7^{b}$ & $0,3^{b}$ & $7,8^{a}$ & $873,7^{*}$ & 0,50 \\
\hline & Coco passado & $2,1^{b}$ & $6,0^{\mathrm{a}}$ & $1,2^{b}$ & $35,2^{*}$ & 1,51 \\
\hline & Ácido & $6,1^{a}$ & $0,7^{c}$ & $2,4^{b}$ & $83,1^{*}$ & 1,06 \\
\hline & Doce & $3,3^{b}$ & $6,1^{a}$ & $2,4^{b}$ & $23,5^{*}$ & 1,39 \\
\hline
\end{tabular}

* significativo ao nível de $5 \%$.

DMS = diferença mínima significativa do teste de Tukey ao nível de 5\%. As médias das amostras acompanhadas pela mesma letra não diferem entre si pelo teste de TUKEY. Amostra 1 = Água-de-coco resfriada.

Amostra 2 = Água-de-coco esterilizada.

Amostra 3 = Água-de-coco congelada.

As tendências sugeridas pelo gráfico aranha (Figura 5) podem ser melhor visualizadas na Figura 6. No gráfico da ACP cada amostra de água-decoco é representada por um triângulo, em que cada vértice corresponde ao valor médio atribuído pela equipe sensorial para cada repetição. Amostras similares ocupam regiões próximas no gráfico e são caracterizadas pelos vetores (atributos) que se apresentam mais próximos 
delas. Neste estudo, os dois componentes principais explicaram juntos $96,24 \%$ da variabilidade total observada entre as águas de coco.

Verificou-se grande diferença entre o perfil sensorial das três amostras, uma vez que se apresentaram bem distantes umas das outras.

Devido ao tamanho reduzido dos triângulos e a proximidade dos seus vértices pode-se constatar boa repetibilidade de resultados pela equipe treinada. A água-de-coco esterilizada destacou-se das demais por apresentar maior turbidez, aroma pútrido, sabor de coco passado e gosto doce. Por sua vez, a água-de-coco resfriada salientou-se por apresentar mais bolhas, aroma de água tônica e gosto ácido mais intensos. A águade-coco congelada caracterizou-se pela maior presença de partículas, bem como pelo aroma e sabor de ferrugem. Esses resultados foram confirmados pelo teste de Tukey (Tabela 1).

\section{FIGURA 6 - ANÁLISE DE COMPONENTES PRINCIPAIS - EIXOS I E II}

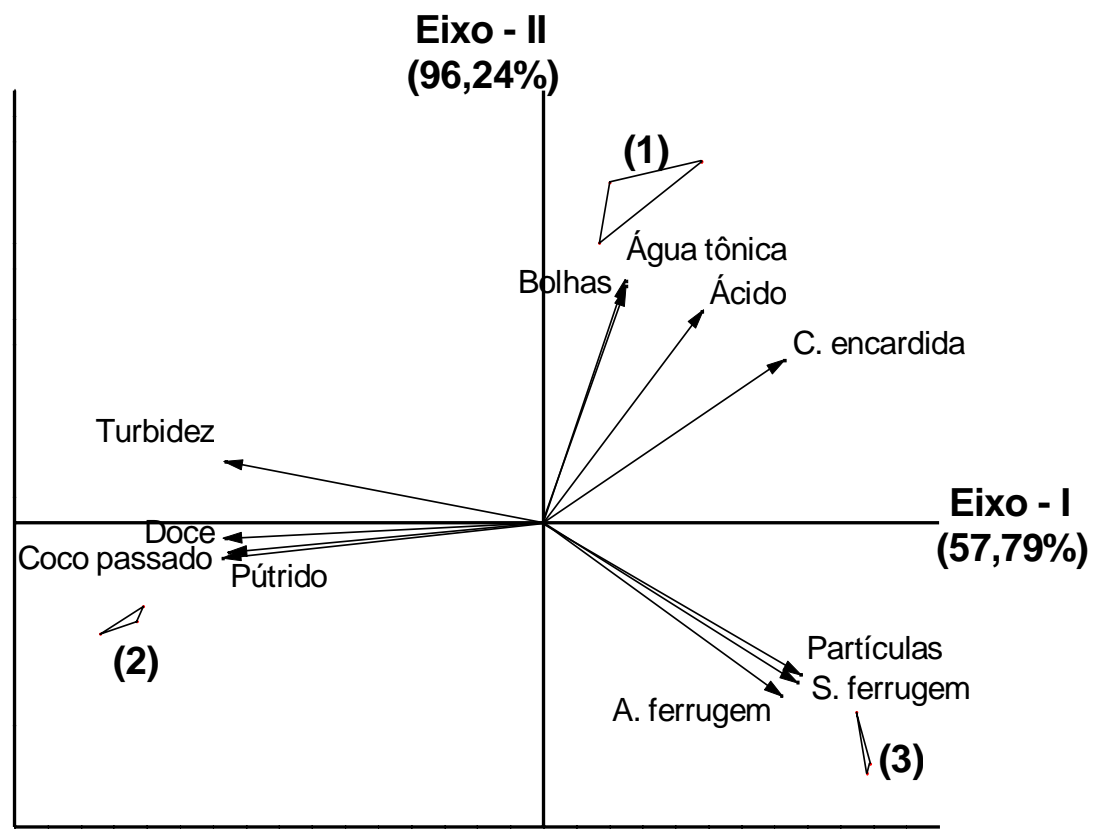

Amostra 1 = Água-de-coco resfriada.

Amostra 2 = Água-de-coco esterilizada.

Amostra 3 = Água-de-coco congelada. 
Maior intensidade para o gosto ácido e aroma de água tônica da águade-coco resfriada pode ser devida à adição de conservadores e acidulantes, conforme consta em sua rotulagem (INS-211, INS-226, INS330 e INS-300, esse último como antioxidante). A coloração encardida pode ser atribuída às reações de escurecimento não-enzimático, como caramelização, reação de Maillard e oxidação do ácido ascórbico (INS300) devido à ação do tratamento térmico. De fato, LEBER (2001) e CAMPOS et al. (1996) atribuíram alterações nas características sensoriais da água-de-coco à presença de aditivos e aplicação de tratamento térmico.

Com relação à água-de-coco esterilizada, provavelmente a maior intensidade dos atributos gosto doce, sabor de coco passado e turbidez pode ser atribuída ao estado avançado de maturação do coco (cerca de 11 meses). Isto pode ser visualizado na Figura 6 cujos vetores que representam esses descritores apresentaram-se próximos uns dos outros, sugerindo correlação positiva entre si. Segundo RANIERI (2000), as águas de coco que sofreram esterilização são provenientes de cocos maduros da variedade híbrida. SREBERNICH (1998) relatou que o coco da variedade híbrida apresenta aumento no teor de sacarose e redução dos teores de glicose e frutose (perda de doçura) em intervalo de maturação de 6 a 10 meses. A indústria realiza a correção do Brix, utilizando frutose. O coco da variedade híbrida também apresenta aumento nos teores de proteína e gorduras com a maturação, o que pode elevar a turbidez e contribuir para o aroma pútrido e sabor de coco passado. Essa matériaprima também contém compostos nitrogenados e ácidos graxos que após degradação podem originar compostos de aroma e sabor desagradáveis, descritos pela equipe treinada como aroma pútrido. A adição de metabissulfito de sódio para evitar o escurecimento enzimático pode contribuir para a presença de sabores e odores estranhos na águade-coco pela formação de compostos de enxofre conforme observado por CAMPOS et al. (1996). Segundo SAPERS (1993), o metabissulfito também pode causar reações alérgicas em alguns indivíduos.

Uma vez que a água-de-coco congelada não sofre nenhum tipo de tratamento térmico, as características de aroma e sabor ferruginoso podem ser atribuídas aos equipamentos utilizados no processo de extração e envase do produto.

Cabe ressaltar que a equipe treinada continha indivíduos provenientes do Norte e do Nordeste, ou que já residiram nessas regiões, além de consumidores habituais de água-de-coco verde. 


\subsection{ACEITAÇÃO DAS AMOSTRAS}

A Figura 7 expressa os resultados da aceitabilidade das amostras de água-de-coco pelos consumidores. A amostra resfriada foi a mais aceita, obtendo $73,3 \%$ de respostas na faixa hedônica de aceitação (gostei ligeiramente a gostei muito), seguida pela amostra esterilizada com $53,3 \%$ também nessa faixa. Já a água-de-coco congelada obteve $63,3 \%$ das respostas na faixa de rejeição (desgostei extremamente a nem gostei/nem desgostei).

\section{FIGURA 7 - NÍVEL DE ACEITAÇÃO DOS JULGADORES PARA A ÁGUA-DE-COCO PROCESSADA}

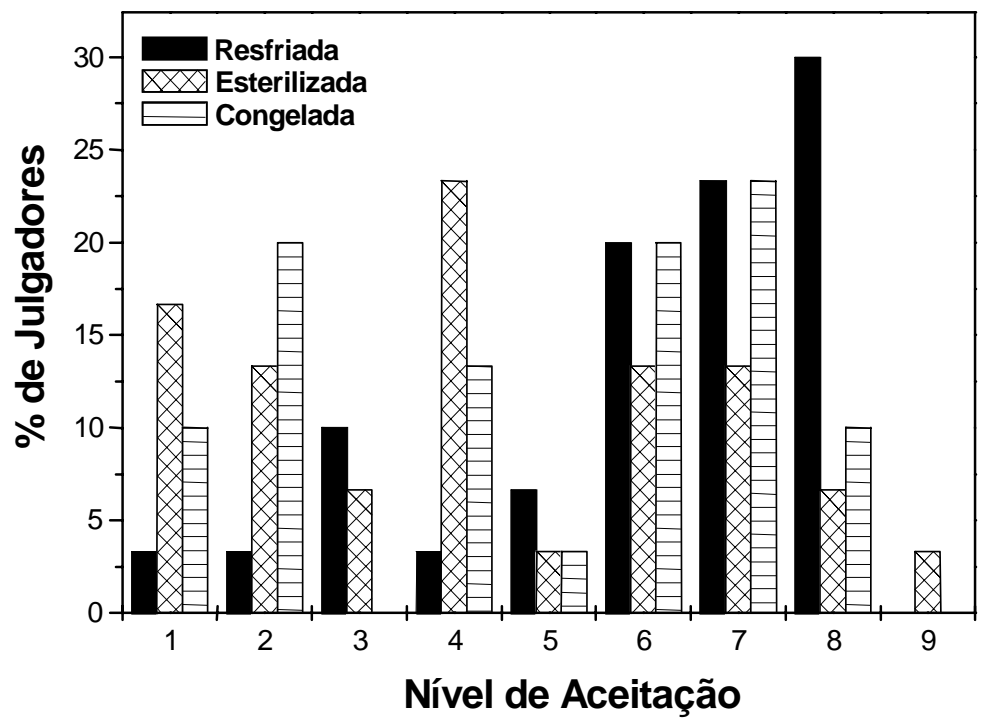

1 = desgostei muitíssimo; 5 = nem gostei/nem desgostei; 9 =gostei muitíssimo .

As médias de aceitação, juntamente com os resultados da análise de variância e do teste de Tukey, estão apresentadas na Tabela 2. Verificouse que a água-de-coco resfriada foi significativamente $(p \leq 0,05)$ mais aceita que a água-de-coco congelada, não diferindo da água-de-coco 
esterilizada a 5\% de significância. Esses resultados estão coerentes com o perfil sensorial da água-de-coco resfriada, caracterizada pela presença de bolhas, coloração encardida, aroma de água tônica e gosto ácido. Certamente esses descritores exerceram influência menos negativa na percepção da água-de-coco verde pelos consumidores, que os atributos das outras duas amostras (ferrugem, pútrido e outros).

\section{TABELA 2 - MÉDIA DE ACEITAÇÃO DOS JULGADORES PARA A ÁGUA- DE-COCO PROCESSADA}

\begin{tabular}{rrrrrr}
\hline Aceitação & Amostra 1 & Amostra 2 & Amostra 3 & F (amostra) & \multicolumn{1}{c}{ DMS } \\
\cline { 2 - 6 } & $6,1^{\mathrm{a}}$ & $4,8^{\mathrm{ab}}$ & $4,3^{\mathrm{b}}$ & $5,65^{\star}$ & 1,324 \\
\hline
\end{tabular}

*Significativo a $5 \%$.

DMS = diferença mínima significativa do teste de Tukey ao nível de 5\%. As médias das amostras acompanhadas pela mesma letra não diferem entre si pelo teste de TUKEY. Amostra 1 = Água-de-coco resfriada.

Amostra 2 = Água-de-coco esterilizada.

Amostra 3 = Água-de-coco congelada.

FRASSETTI et al. (2000) e ARAÚJO et al. (2000) também encontraram baixos valores de aceitação para amostras de água-de-coco congeladas e tratadas termicamente, comercializadas na cidade do Rio de Janeiro.

\section{CONCLUSÃO}

Os resultados do presente estudo permitem concluir que os tratamentos aplicados para o processamento de água-de-coco no Brasil estão conferindo características muito negativas ao produto final. As amostras apresentaram aroma e sabor de ferrugem, de pútrido, de coco passado e gosto ácido, evidenciando baixa aceitação junto aos consumidores. Tais resultados apontam para a necessidade de que sejam pesquisadas melhorias nos processamentos de água-de-coco. Sugere-se realização de estudos sobre a redução do binômio de tempo e temperatura do tratamento térmico, eliminação ou substituição de aditivos, utilização de metodologias não-convencionais de conservação como filtração por membranas, pulso elétrico, alta pressão ou ainda a combinação desses. 


\begin{abstract}
SENSORIAL PROFILE AND ACCEPTANCE OF COCONUT WATER SAMPLES OBTAINED FROM DIFFERENT MANUFACTURING PROCESSES

The objective of the present study was to characterize some coconut water samples commercialized in supermarkets of the Southeastern (Brazil) region and to correlate such characteristics to the different manufacture technologies employed. Quantitative descriptive analysis was utilized to determine the sensorial profile of three commercial coconut water brands (cooled, frozen and sterilized), available in the market of Campinas-SP (Brazil) and the consumer acceptance of the samples was evaluated applying an affection test. It was observed that the samples were deprived of the sensorial characteristics, presenting strange flavors and aromas (off-flavors) described as tonic water, rust and putridity, as well as a low acceptance. These result can be directly related to the type of processing applied to the product, evidencing the necessity of a fast improvement of the coconut water processing.
\end{abstract}

KEY-WORDS: COCONUT WATER; SENSORIAL ANALYSIS.

\title{
REFERÊNCIAS
}

1 ARAGÃO, W. M. (Ed.). Coco: pós-colheita. Aracajú: Embrapa Tabuleiros Costeiros, Brasília: Embrapa Informação Tecnológica, 2002. $76 \mathrm{p}$.

2 ARAÚJo, A. H.; FONTENEle, A. M. M.; MOtA, A. P. M.; DANTAS, F. F.; VERRUMA-BERNARDI, M. R. Análise sensorial de água-de-coco in natura em comparação à pasteurizada. In: CONGRESSO BRASILEIRO DE CIÊNCIA E TECNOLOGIA DE ALIMENTOS, 17., 2000, Fortaleza. Livro de Resumos... Fortaleza: SBCTA, 2000. v. 1.

3 CAMPOS, C.F.; SOUZA, P.E.A.; COELHO, J.V.; GLÓRIA, M.B.A. Chemical composition, enzyme activity and effect of enzyme inactivation of flavor quality of green coconut water. Journal of Food Processing and Preservation, n. 20, p. 487-500. 1996.

4 DAMÁSIO, M. H.; COSTELL, E. Analisis sensorial descriptiva: generación de descritores y selección de catadores. Revista Agroquimica Technol. Alim. Valencia, v. 31, n. 2, p. 165 -178, 1991.

5 FRASSETTI, J.; TÓRTORA, J.C.O.; GREGÓRIO, S.R. Aceitação de água-de-coco in natura e processada. In: CONGRESSO BRASILEIRO DE CIÊNCIA E TECNOLOGIA DE ALIMENTOS, 
17., 2000, Fortaleza. Livro de Resumos... Fortaleza: SBCTA, 2000. v. 1.

6 LEBER, A. S. M. L. A variação da estabilidade da água-decoco (Cocus nucifera) em garrafas de polietileno tereftalato (PET), estocadas congelada e resfriada. Campinas, 2001. 151 p. Dissertação (Mestrado em Tecnologia de Alimentos), Faculdade de Engenharia de Alimentos, Universidade Estadual de Campinas.

7 MEDINA, J.C.; GARCIA, J.L.M.; DE MARTIN, Z.J.; KATO, K.; TERUO, P.; TURATTI, J.M.; SANTOS, L.C.; SILVA, M.T.C.; CANTO, W.L.; BICUDO NETO, L.C.; MORETTI, V.A. Coco: da cultura ao processamento e comercialização. Campinas: ITAL, 1980. 285 p. (Série Frutas Tropicais, 5).

8 MOSKOWITTZ, H. R. Product testing and sensory evaluation of foods: marketing and r. \& d. approaches. Westport: Food and Nutrition Press, 1983. 605 p.

9 RANIERI, M. Água de côco: um mercado em crescimento. Engarrafador Moderno, n. 74, p. 24-28, 2000.

10 SAPERS, G. M. Browing of foods: control by sulfites, antioxidants, and other means. Food Technology, v. 47, n. 10, p. 75-84, Oct. 1993.

11 SAS Institute Inc. Statistical Analytical System. Cary, North Carolina, 1996. Version 6.12.

12 SILVA, M. A. A. P. Análise sensorial. Campinas: FEA/UNICAMP, 2002.

13 SOCÔco S/A Indústrias Alimentícias. Super coco. Disponível em: http://www.sococo.com.br/o coco/super_coco/. Acesso em: 10 jul. 2001.

14 SREBERNISH, S.M. Caracterização física e química da água de fruto de coco (Cocos nucifera), variedades gigante e híbrido PB-121, visando o desenvolvimento de uma bebida com características próximas às da água-de-coco. Campinas, 1998. 189 p. Tese (Doutorado em Tecnologia de Alimentos), 
Faculdade de Engenharia de Alimentos, Universidade Estadual de Campinas.

15 STONE, H; SIDEL, J.L. Sensory evaluation practices. Orlando: Academic Press, 1985. 287 p. 